\title{
REPERCUSSÓES EMOCIONAIS DO CYBERBULLYING: UM ESTUDO DE AUTORRELATOS
}

\author{
REPERCUSIONES EMOCIONALES \\ DEL CYBERBULLYING: UN ESTUDIO \\ DE AUTORRELATOS
}

\section{EMOTIONAL REPERCUSSIONS OF CYBERBULLYING: A STUDY OF SELF REPORTS}

\author{
Joana PESSOA $A^{1}$ \\ Lara FERREIRA ${ }^{2}$ \\ Marta RAMINHAS \\ Miguel FRANCISCO ${ }^{4}$ \\ Paula da Costa FERREIRA \\ Sidclay Bezerra de SOUZA
}

${ }^{1}$ Aluna do Mestrado Integrado em Psicologia - Faculdade de Psicologia, Universidade de Lisboa. Alameda da Universidade, 1649-013 Lisboa, Portugal. E-mail:

${ }^{2}$ Aluna do Mestrado Integrado em Psicologia - Faculdade de Psicologia, Universidade de Lisboa. Alameda da Universidade, 1649-013 Lisboa, Portugal. E-mail:

${ }^{3}$ Aluna do Mestrado Integrado em Psicologia - Faculdade de Psicologia, Universidade de Lisboa. Alameda da Universidade, 1649-013 Lisboa, Portugal. E-mail:

${ }^{4}$ Aluno do Mestrado Integrado em Psicologia - Faculdade de Psicologia, Universidade de Lisboa. Alameda da Universidade, 1649-013 Lisboa, Portugal. E-mail:

5 CICPSI, Faculdade de Psicologia, Universidade de Lisboa. Alameda da Universidade, 1649-013 Lisboa, Portugal (Investigadora de Pós-doutoramento com bolsa pela Fundação para a Ciência e Tecnologia (SFRH/BPD/110695/2015) no Grupo de Psicologia da Educação e Orientação - PEO, através do Programa de Estudos sobre E-mail: paula.costa.ferreira@gmail.com;

${ }^{6}$ Professor Colaborador do Programa de Pós-graduação em Psicologia (PPG-Psi) e Pós-doutorando da Universidade Federal de Pernambuco (UFPE) através do Programa Nacional de Pós-Doutorado da CAPES (PNPD/CAPES); Doutor em Psicologia, Especialidade em Psicologia da Educação pela Faculdade de Psicologia




Com o aparecimento das novas tecnologias, também novas formas de foram surgindo, nomeadamente $o$. Atualmente, já são muitos os estudos sobre esta recente forma de agressão. No entanto, ainda não são suficientes para abranger todas as suas vertentes. Assim sendo, este estudo pretende focar-se nas repercussóes emocionais do, mais especificamente nas emoçóes negativas provenientes da vitimização do mesmo. Nesta investigaçáo qualitativa foram utilizados autorrelatos de vítimas de , dos quais foi retirada informação sobre as emoçóes reportadas pelas vítimas, de modo a cruzar essa informaçáo com outra investigação na área. A amostra utilizada foi de 15 participantes, sendo a sua maioria pré-adolescentes e adolescentes. Os resultados mostraram que, em grande parte dos casos, é possível encontrarem-se várias emoçôes interligadas. Concluiu-se, também, que as duas emoçóes mais reportadas pelas vítimas são a tristeza e o medo. Este estudo traz uma melhor compreensáo das consequências emocionais negativas provocadas pelo, pois expande o espectro das repercussóes emocionais nas vítimas.

Palavras-chave: Cyberbullying. Bullying. Repercussōes. Emoçôes Negativas. Emoçôes Reportadas. Autorrelatos.

\section{INTRODUÇÃO}

Nas últimas décadas, com a existência de um grande avanço tecnológico, as tecnologias da informação e comunicação (TIC) revolucionaram o mundo, nascendo, assim, novas formas de comunicar e interagir com as pessoas. Atualmente, as TIC têm tido, cada vez mais, um papel fundamental na vida quotidiana da grande maioria da

da Universidade de Lisboa - (FP-ULisboa). Atua como investigador da linhas de pesquisa: "” inserida no Laboratório de Interação Social Humana (LabInt) da UFPE; e "Aprendizagem em Rede" (GRUPAR), da da Universidade Federal de Juiz de Fora (UFJF); Também é membro colaborador do CICPSI, Faculdade de Psicologia da Universidade de Lisboa - (FP-ULisboa). E-mail: ssouza@campus. ul.pt. 
população ocidental. Contudo, independentemente de todos os benefícios e facilidades que estas trouxeram, muitos foram os novos perigos e riscos que começaram a surgir, nomeadamente novas formas de vitimização, como o .

Sendo este um conceito recente, muitas são, ainda, as definiçốes para esta forma de, no entanto, a maioria vai ao encontro da visão de Smith et al. (2008), que define o como sendo um "ato ou comportamento agressivo e intencional realizado por um grupo ou um individuo, através de um meio eletrónico, repetidamente e ao longo do tempo contra uma vítima que não consegue defender-se facilmente". Por outras palavras, o é uma forma de agressão realizada através de um equipamento eletrónico que pode ser realizada tanto por um indivíduo, como por um grupo de indivíduos, e que se repete prolongadamente, náo consistindo num ato único e esporádico. Distingue-se do tradicional na medida em que este é baseado em agressões presenciais, desde verbais a físicas.

Alguns tipos de apresentados por Menesini e Spiel (2012) foram: e-mails ou SMS ofensivos; insultos por ou ; partilha e/ou utilização de fotografias ou vídeos não autorizados; exclusão de redes socias; apropriação de credenciais e da identidade e utilização das mesmas para fins pejorativos. Para além destes, no site Bullying Statistics são expostas outras formas de , como espalhar rumores online ou através de SMS sobre alguém; fingir ser uma pessoa que não se é online para magoar o outro; e circular fotos ou mensagens sexualmente explícitas de alguém.

Atualmente, já se verifica uma vasta investigação relativa a este tema, nomeadamente no que se refere às consequências do (KOWALSKI; WHITTAKER, 2015) e aos seus antecedentes (CROSS; LESTER; BARNES, 2015), às caraterísticas das vítimas e dos agressores (KOWALSKI; WHITTAKER, 2015), às crenças dos relativamente ao impacto das suas açôes em comparação com o impacto reportado pelas vítimas (GUALDO et al., 2015), à comparação das consequências do tradicional com as do (BOURDEAUDHUIJ;




JACOBS; DESMET; GUNTHER, 2015) e às repercussóes comportamentais, emocionais e psicofisiológicas que o traz às suas vítimas (CARAVITA et al., 2015).

Num estudo sobre o impacto emocional do (GUALDO et al., 2015), foram analisadas as diferenças de perceção do e do consoante o papel desempenhado (vítima, agressor e agressorvítima) e o contexto da agressão. O estudo mostra que as consequências emocionais não acontecem apenas nas vítimas, mas nos agressores também. É mencionado um estudo em que $64 \%$ das vítimas de sentiam que os agressores se sentiriam bem consigo mesmos, contentes, brilhantes ou inteligentes pela agressão; no entanto, apenas $35 \%$ dos agressores reportaram ter essas reaçôes, podendo isto sugerir que alguns agressores são também afetados negativamente pelas suas açóes, o que pode ser bastante interessante para futuros estudos. A emoção mais reportada pelas vítimas de neste estudo foi a tristeza, seguida pela rejeição. $\mathrm{O}$ estudo concluiu que as vítimas que experienciaram tanto como avaliam o como tendo um maior impacto negativo do que as vítimas que apenas sofreram de . Isto pode ter várias explicaçóes, uma delas sendo que as experiências negativas vivenciadas - sofrer na escola e o agressor começar também a praticar - podem ser cumulativas e dar uma perceção mais negativa do. Outra justificação é que o remete para situaçóes do ocorrido e isso afeta mais a vítima em questão.

A nível das consequências sociais, os adolescentes vítimas dos seus pares, tanto online () como através de tradicional, têm maior tendência para reportar stress emocional, sintomas de ansiedade e depressão, isolamento social, solidáo e para demonstrar aumento da abstinência escolar e fracos resultados académicos (CROSS; LESTER; BARNES, 2015).

Consideramos relevante o artigo de Souza et al (2016) para a presente investigaçáo, não só por tentar compreender de que forma as vítimas experienciam o tanto no nosso país, como no Brasil, tomando, ainda, em consideração as estratégias consideradas e seguidas pelas mesmas. 
Também aqui foram consideradas atitudes de intimidaçáo e apropriaçáo de imagem para o conceito de , assim como um crescente aumento do fenómeno em diversos países (SOUZA et al., 2016) - o que se apresenta como um fator gravíssimo em termos sociais.

De forma a que houvesse uma maior compreensão deste fenómeno, foi utilizado um Questionário do para o Ensino Superior (QCES), adaptado para o Brasil, com 1340 participantes. Através do mesmo foi possível perceber que, tanto em Portugal, como no Brasil, a maior percentagem das vítimas incidia sobre o género feminino $(68.7 \%$ no Brasil e $67.4 \%$ em Portugal), havendo uma diferenciação quanto aos comportamentos de, sendo que a maior percentagem de ameaças e assédios de caráter sexual ocorre no Brasil, relativamente a Portugal.

Relativamente às emoçóes mais sentidas pelas vítimas, verificou-se existir uma maior frequência de emoçóes do tipo negativo (culpa, preocupação, sensação de indefesa, raiva e vontade de vingança) no Brasil relativamente a Portugal (SOUZA et al., 2016), o que evidência claramente uma maior perceção de humilhação, mas também uma maior procura de ajuda profissional relativamente ao nosso país. Sendo as reaçóes ao fenómeno de manifestamente diferentes nos dois países, existe, no Brasil, uma notória tendência superior para o confronto ou, por outro lado, para o desprezo para com o agressor, assim como a procura de ajuda profissional; em Portugal, a inclinação é para uma toma de medidas mais extremas, sem referência ao apoio profissional, o que consideramos especialmente interessante e que nos leva a pensar que poderá estar diretamente associado a fatores culturais.

Também o artigo de Ortega, et al. (2012) nos pareceu igualmente pertinente para a investigação que apresentamos. O presente artigo é interessante por tentar aceder às consequências emocionais do fenómeno de e nas vítimas, através de uma abordagem direta à vítima, assim como uma

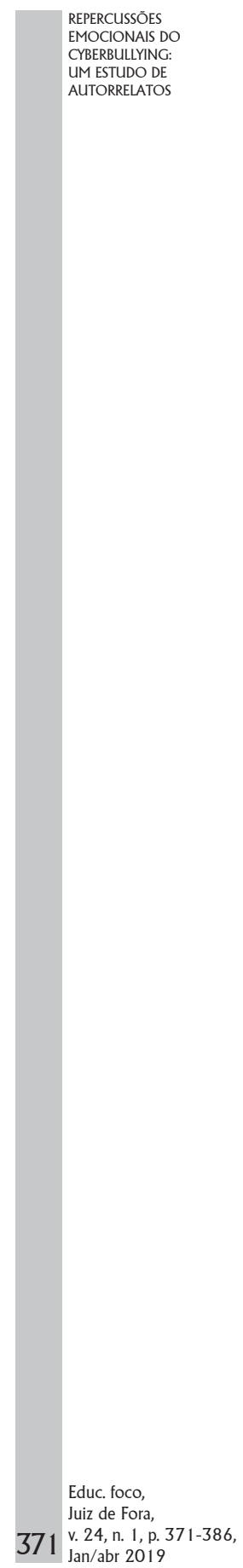


abordagem centrada nas variáveis, que permitiu aos autores analisar a influência das mesmas.

Este estudo, Ortega et al., (2012) pretendeu investigar o impacto emocional tanto do tradicional como do nas vítimas, através da comparação de três países: Itália, Espanha e Inglaterra. Tendo em consideração que a nossa investigação pretende perceber as causas emocionais do, relativamente a este artigo vamos somente focar-nos nas mesmas. Os autores do mesmo consideraram o em duas categorias: através do telemóvel e via Internet. Muito embora na nossa investigação não tenhamos distinguido as formas possíveis deste tipo de violência, consideramos que este estudo é pertinente por nos dar acesso à percentagens de vítimas de cyberbullying que reportaram cada emoção, na amostra total por país.

Assim sendo, a nível de via telefone, com uma amostra total de 338 participantes, nos três países, 8\% mostraramse inseguros, 9.2\% sozinhos, $9.5 \%$ embaraçados, $10.7 \%$ depressivos, $13.3 \%$ assustados, sendo igual a percentagem para stressados, $18.3 \%$ chateados, $19.5 \%$ preocupados, $25.4 \%$ não incomodados e finalmente, $35.8 \%$ sentiram raiva face a este tipo de violência.

Relativamente ao via Internet, com uma amostra de 406 indivíduos, nos três países, 7.1\% sentiram-se indefesos, $8.9 \%$ sozinhos, $10.3 \%$ deprimidos, $11.1 \%$ embaraçados, $11.3 \%$ stressados, $12.8 \%$ assustados, $15.5 \%$ preocupados, $19.5 \%$ chateados e finalmente, $35.7 \%$ sentiram-se indiferentes face a este tipo de agressão.

Podemos desta forma observar que, relativamente ao via telefone a emoção mais reportada foi a raiva (35.8\%), seguida da indiferença (25.4\%), enquanto que as emoçóes mais reportadas no caso do via Internet foram precisamente as contrárias - estando a maior percentagem associada à indiferença $(35.7 \%)$, seguindo-se a raiva (33.7). fator que consideramos interessante pelo facto de, em ambos os casos, as emoçóes mais sentidas pelas vítimas serem antagónicas. 
Através da análise e observação de todas as emoçôes sentidas e reportadas, é-nos possível perceber o grande impacto que este tipo de violência tem nas pessoas - passando por sentimentos de raiva, solidáo, insegurança e tendências depressivas, entre muitas outras. É com o objetivo de perceber melhor esse impacto proveniente da vitimizaçáo do que também Patchin e Hinduja (2006) realizaram um estudo focado no relato das experiências de dos participantes. Com uma amostra de 384 jovens, com menos de 18 anos, concluíram que mais de $30 \%$ foram vítimas de e que muitas delas sofreram de experiências prévias como vítimas de Das vítimas, cerca de $42 \%$ ficaram frustradas, quase $40 \%$ zangadas e $27 \%$ sentiram-se tristes, após a exposição a este tipo de violência, sendo que quase um terço relatou ter prejudicado a sua vida escolar e familiar. É clara a gravidade e importância deste assunto, sendo que é um tipo de violência cada vez mais corrente e com uma enorme necessidade de sensibilizaçáo para que se possa levar à sua eliminação.

Os impactos do são efetivamente graves, afetando principalmente a saúde mental das vítimas. Kowalski e Whittaker (2015) vêm reforçar a seriedade deste tipo de violência para a vítima em questáo, mostrando que a mesma apresenta, como consequências do , tendências suicidas, depressão, baixa autoestima, aumento de ansiedade, isolamento, sintomas somáticos, abstinência escolar e baixo desempenho associado, assim como o uso de alucinogénios, incluindo drogas e álcool. Também Cross, Lester e Barnes (2015) focam precisamente esta ideia: através da recolha de dados de 1504 alunos australianos, entre os 13 e os 15 anos, que responderam a um questionário online, foi possível perceber que a percentagem de jovens que reportavam serem vítimas (tanto de e em simultâneo, como de apenas ) se manteve estável ao longo de três anos - havendo uma dificuldade associada de reportar os problemas emocionais e de falar com alguém sobre os acontecimentos - especialmente

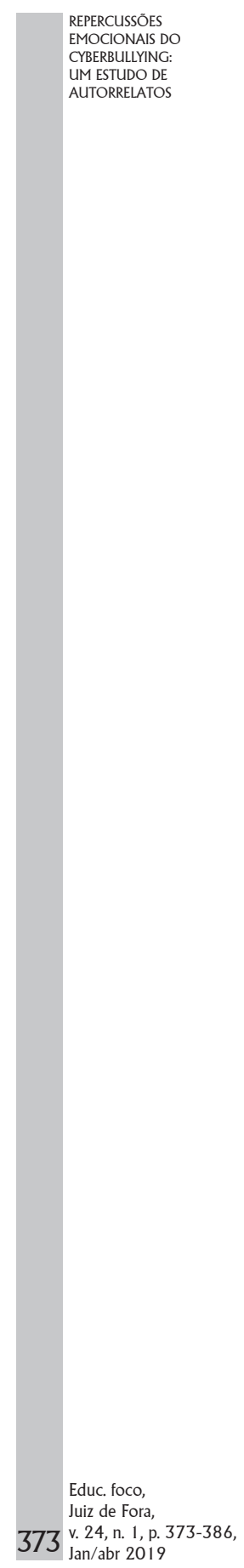


em raparigas, sendo frequente a ausência à escola decorrente deste tipo de vitimização.

Considera-se relevante e pertinente estudar as repercussóes comportamentais, emocionais e psicofisiológicas do , tentando-se perceber se a exposição a situaçóes deste tipo produz, ou não, nos jovens, consequências como maiores níveis de stress, emoçôes negativas e défices de atenção em comparação com outras interaçôes entre jovens, como no caso do . O artigo de Caravita et al. (2016) atenta precisamente nisto: os dois estudos experimentais foram realizados de forma a examinar respostas emocionais, fisiológicas e de comportamento associadas a situaçôes tanto de , como de , assim como de interações entre pares. Através dos mesmos, foram captadas respostas fisiológicas de elevado stress a situaçóes de exposição a e, em particular, de, levando simultaneamente a maiores emoções de raiva, vergonha e medo.

Neste estudo baseamo-nos no capítulo de Reio e Ortega (2016), que sintetiza muita da investigação mais recente na área do e se foca nas emoçóes negativas reportadas pelas vítimas desta forma de violência, sendo que os autores definem emoçóes negativas como uma das seis emoçóes básicas de Ekman e Friesen (1971) - felicidade, tristeza, surpresa, medo, nojo e raiva - ou como sendo um sentimento negativo derivado destas seis. As quatro emoçóes negativas apresentadas por Reio e Ortega (2016) são, deste modo, a tristeza, o medo, o nojo e a raiva.

Diante do que fora explicitado, elencamos as seguintes questóes de investigação que serviram como base para este estudo:

Q1 - Quais são, deste modo, as repercussóes emocionais do?

Q2 - Serão somente as quatro emoçôes negativas apresentadas por Reio e Ortega (2016) as principais emoçóes reportadas pelas vítimas? 
Desta forma, o objetivo deste estudo passa por, através da análise de autorrelatos de vítimas de que recolhemos da Internet, perceber se as quatro emoçóes negativas (Ekman; Friesen, 1971) apresentadas por Reio e Ortega (2016) - e consideradas emoçôes universais por Ekman e Friesen (1971) - sấo efetivamente as mais reportadas pelas vítimas e perceber, ainda, que outras emoçóes, para além destas, são também sentidas pelas mesmas. Por fim, vamos relacionar estas quatro emoçóes - tristeza, medo, nojo e raiva - com as outras emoçóes relatadas pelas vítimas, e perceber quais são efetivamente as mais reportadas nesses mesmos autorrelatos, de modo a percebermos, assim, quais as consequências emocionais causadas pelo nas vítimas. Com isto, tencionamos aprofundar o conhecimento sobre as consequências emocionais do ,de modo a compreender melhor como este afeta as vítimas.

\section{Método}

\section{Participantes}

Este estudo baseou-se em autorrelatos, sendo que a amostra utilizada foi de 15 participantes. As idades dos participantes variam entre 11 e 33 anos. Dentro deste intervalo de idades, $80 \%$ dos participantes (12 participantes) são préadolescentes e adolescentes, com idades compreendidas entre os 11 e os 19 anos. Aproximadamente 73\% dos participantes (11 participantes) são do sexo feminino e 27\% (4 participantes) são do sexo masculino. Dos participantes, 6 são dos Estados Unidos da América, 5 do Brasil, 1 é da Austrália, 1 da Nova Zelândia, 1 do Omã e 1 participante é de origem desconhecida.

\section{ArTefactos}

A recolha de autorrelatos foi feita, sendo que o principal critério de escolha foi a presença, no autorrelato, de emoçóes sentidas pela vítima na altura em que sofreu de . Utilizámos dois tipos de autorrelatos na nossa análise: em formato de vídeo (recolhidos do ) e em texto escrito (recolhidos de variados, blogues e fóruns da Internet). 


\section{Análise de Dados}

Inicialmente, os autorrelatos em formato de vídeo foram transcritos palavra por palavra para formato de texto, de modo a serem posteriormente analisados. Nesta fase - em que os autorrelatos em formato de vídeo foram transformados em texto - não houve qualquer interpretação, alteração ou distorção do conteúdo. Posteriormente, a análise dos dados recolhidos nos autorrelatos foi feita minuciosamente através da leitura repetida - por cada um dos autores - de cada autorrelato, de modo a ser possível a identificaçáo de todas as emoçóes sentidas pelas vítimas. Por fim, sendo que muitas vezes as emoçóes estavam presentes nos autorrelatos apenas implicitamente, foi necessária uma discussão entre os autores de modo a se atingir um consenso relativamente às emoçóes presentes em cada autorrelato.

\section{ApresentaÇão e Discussão dos Resultados}

Para a análise dos resultados, foi contruída primeiramente uma tabela onde compilámos todos os dados registados com a análise dos autorrelatos (apresentados na Figura 1), incluindo o número de participantes e as emoçóes registadas, divididas entre as quatro emoçóes que retirámos de Reio \& Ortega (2016) e as restantes, que fomos encontrando nos autorrelatos à medida que os analisávamos. 
Figura 2. Apresentação de Resultados

\begin{tabular}{|c|c|c|c|c|c|c|c|c|c|c|c|c|c|}
\hline & \multicolumn{4}{|c|}{$\begin{array}{l}\text { Emoçoes Negativas } \\
\text { (Reio \& Ortega, 2016) }\end{array}$} & \multicolumn{9}{|c|}{$\begin{array}{c}\text { Emoçôes Reportadas } \\
\text { (Autorrelatos) }\end{array}$} \\
\hline & Medo & Nojo & Raiva & Tristeza & Vergonha & Surpresa & Dor & Culpa & Desapontamento & Frustracão & Desgosto & Vingança & Angustia \\
\hline Participante 1 & & & & $\mathrm{x}$ & & & & & & & & & \\
\hline Participante 2 & & & $\mathrm{x}$ & $\mathrm{x}$ & & & $\mathrm{x}$ & $\mathrm{x}$ & & & & $\mathrm{x}$ & \\
\hline Participante 3 & $\mathrm{x}$ & & & $\mathrm{x}$ & $\mathrm{x}$ & & & & & $\mathrm{x}$ & & & \\
\hline Participante 4 & & $\mathrm{x}$ & & $\mathrm{x}$ & $\mathrm{x}$ & & & & $x$ & & & & \\
\hline Participante 5 & $\mathrm{x}$ & $\mathrm{x}$ & & $\mathrm{x}$ & & & & & $\mathrm{x}$ & & $\mathrm{x}$ & & $\mathrm{x}$ \\
\hline Participante 6 & $\mathrm{x}$ & & & $\mathrm{x}$ & $\mathrm{x}$ & & & & $\mathrm{x}$ & & $\mathrm{x}$ & & \\
\hline Participante 7 & & $x$ & & $\mathrm{x}$ & & & & & $\mathrm{x}$ & & $\mathrm{x}$ & & \\
\hline Participante 8 & & & & $\mathrm{x}$ & $\mathrm{x}$ & & & & & & & & \\
\hline Participante 9 & & & & & & $\mathrm{x}$ & & & & & & & \\
\hline Participante 10 & $x$ & & & & & & & & & & & & \\
\hline Participante 11 & & & & $\mathrm{x}$ & & & & & & & & & \\
\hline Participante 12 & $\mathrm{x}$ & & $\mathrm{x}$ & $\mathrm{x}$ & & & & & & & & & \\
\hline Participante 13 & $\mathrm{x}$ & & & $\mathrm{x}$ & & & & & & & & & \\
\hline Participante 14 & $\mathrm{x}$ & & & $\mathrm{x}$ & & & & & & & & & \\
\hline Participante 15 & $\mathrm{x}$ & & & $\mathrm{x}$ & & & & & & & & & \\
\hline Total: & 8 & 3 & 2 & 13 & 4 & 1 & 1 & 1 & 4 & 1 & 3 & 1 & 1 \\
\hline
\end{tabular}

Fonte: Os Autores.

De seguida, optámos por criar um esquema (Figura 2) onde, de forma simples e intuitiva, conseguíssemos expor os nossos resultados, ou seja, a relação entre as quatro emoçôes de Reio \& Ortega (2016) e as restantes que recolhemos nos autorrelatos. Com este esquema é possível observar que emoçóes aparecem relacionadas entre si, e quais as que náo apresentam qualquer relação.

Através da análise do esquema conceptual e da tabela de resultados acima apresentados, conseguimos observar que a tristeza - uma das quatro emoções negativas sugeridas por Reio e Ortega (2016) - é a emoção mais reportada pelas vítimas de na nossa amostra (presente em 13 autorrelatos), associando-se com todas as outras emoçóes reportadas, exceto com a surpresa - que não se relaciona com nenhuma outra emoção. Contudo, segundo o estudo de Caetano et al. (2016), quando confrontados com as várias possíveis emoçóes sentidas pelas vítimas, foram poucos os agressores que a reconheceram como sendo das mais reportadas pelas vitimas.

O medo - também uma das quatro emoções negativas sugeridas por Reio e Ortega (2016) - é a segunda emoção mais reportada (presente em 8 autorrelatos) e a que mais se liga 
às outras emoçóes reportadas pelas vítimas, com exceção do sentimento de vingança e da surpresa. O estudo de Caravita et al. (2016) mostrou que a exposição a situaçōes de conduz a um elevado nível de stress, podendo resultar num aumento do sentimento de medo, entre outros. O medo também pode ser proveniente da possível falta de controlo sobre a situaçáo (CAETANO et al., 2016).

Figura 2. Relações entre as emoçóes apontadas pelas vítimas de cyberbullying nos autorrelatos.



Fonte: Os Autores.

A vergonha e o desapontamento são as duas emoçôes que se seguem na lista das mais reportadas (cada uma presente em 4 autorrelatos) - e náo o nojo e a raiva, como seria de esperar segundo Reio e Ortega (2016) -, estando todas elas associadas à tristeza, ao medo e ao nojo.

$\mathrm{O}$ nojo, o desgosto (ambas as emoçóes presentes em 3 autorrelatos) e a raiva (presente em 2 autorrelatos) são as que se seguem, sendo que o nojo se associa à vergonha, ao desapontamento, ao desgosto e à angústia. $\mathrm{O}$ desgosto, para além de se associar ao nojo, também se associa ao medo e à tristeza, enquanto que a raiva - emoçáo desencadeada pelo elevado nível de stress que as situaçôes de suscitam na vítima (Caravita et al., 2016) - surge associada à dor, à culpa e à vingança. 
A surpresa, a dor, a culpa, a frustração, a vingança e a angústia são emoçốes que apenas aparecem cada uma em um autorrelato, sendo que todas estas emoçóes - à exceção da surpresa, que não se associa com nenhuma outra emoção estấo associadas ao medo.

As quatro emoçóes negativas - tristeza, medo, raiva e nojo (REIO; ORTEGA, 2016) - associam-se muitas vezes às mesmas emoçôes reportadas pelas vítimas. Contudo, o medo e a raiva nunca se encontram juntos nos autorrelatos, o que sugere a existência de dois polos: num desses polos está o medo, que se associa a todas as outras emoçóes reportadas pelas vítimas, exceto a culpa, a vingança e a surpresa; no outro polo está a raiva, que apenas se associa com a dor (esta emoção associa-se tanto com o medo, como com a raiva), com a vingança e com a culpa - as duas únicas emoçóes, para além da surpresa, que não se associam com o medo.

Verificou-se, ainda, que os sentimentos de nojo e raiva nunca aparecem sem ligação a outras emoçóes, sejam elas as quatro emoçóes negativas apresentadas por Reio e Ortega (2016), sejam as restantes emoçóes reportadas pelas vítimas. Contrariamente, a tristeza e o medo são as únicas emoçóes que surgiram sem associaçấo a outras, em alguns dos autorrelatos, reforçando a ideia de que estas são as emoçôes mais comuns e que prevalecem em quase todas as vítimas de .

A surpresa foi a única emoção que se verificou não estar relacionada com nenhuma outra, pelo que no esquema concetual se encontra sem ligaçóes às outras emoçóes. Esta emoção, que não foi considerada uma das quatro emoçôes negativas (REIO; ORTEGA, 2016), é, contudo, umas das seis emoçóes básicas de Ekman e Friesen (1971). O anonimato, que é caraterístico do , normalmente leva a medo por parte das vítimas; contudo, nalguns casos, este mesmo anonimato pode conduzir a que as vítimas não se sintam táo afetadas e, por isso, demonstrem menos emoções negativas (Reio; Ortega, 2016). No entanto, neste caso em particular, a vítima, para além de se sentir surpreendida com os ataques de que estava




a ser alvo, sentiu-se também surpreendida posteriormente, ao descobrir que os agressores eram seus amigos íntimos.

Os sentimentos de raiva, tristeza, dor, culpa e vingança surgiram em simultâneo apenas uma vez, como podemos observar na tabela de frequências, num caso em que a vítima se sentiu táo injustiçada com a sua situação que decidiu vingar-se dos seus agressores, tornando-se ela na agressora. No entanto, depois do sucedido, sentiu-se arrependida, conclusão que podemos deduzir visto que a vítima confessou que, após a vingança, se sentiu ainda pior e náo solucionou nada.

Constatou-se, também, que o nojo, sempre associado à tristeza, é uma emoção que surge permanentemente associada à própria vitima. Isto é, a pessoa sente nojo de si mesma, proveniente de uma baixa autoestima causada pela constante agressão e múltiplos insultos. Já Kowalski e Whittaker (2015) apresentaram como consequências do depressão e baixa autoestima, dados estes que entram em conformidade com os dados da nossa investigação.

No nosso estudo, as quatro emoçóes negativas mais reportadas foram a tristeza $(87 \%)$, o medo $(53 \%)$, a vergonha (27\%) e o desapontamento (27\%). No livro de Reio e Ortega (2016), é mencionado um estudo de Ortega (2009) em que as três emoçôes negativas mais reportadas foram a raiva $(31,3 \%)$, a preocupação $(23,9 \%)$ e, ainda, o sentimento de transtorno $(22,4 \%)$ para participantes entre os 12 e os 17 anos que sofriam de através do telemóvel. Para participantes da mesma idade, mas que sofriam de através da Internet, as três emoções mais reportadas foram a raiva $(29 \%)$, o transtorno $(17,1 \%)$ e a preocupação $(15,4 \%)$. Num outro estudo de um artigo de Ortega et al. (2012), já referido anteriormente, o através do telemóvel provocou essencialmente sentimentos de raiva (35.8\%), preocupação (19.5\%), aborrecimento (18.3\%), medo e stress (ambos com 13.3\%); contudo, 25.4\% das vítimas disseram não se sentir incomodadas face a este tipo de agressão. No via Internet, 35.7\% sentiram-se indiferentes perante a situação, mas ainda assim $19.5 \%$ das vítimas 
sentiram-se chateadas, $15.5 \%$ preocupadas, $12.8 \%$ assustadas, $11.3 \%$ stressadas e $11.1 \%$ embaraçadas. De todos estes dados, podemos concluir que as consequências emocionais do não são uma realidade estável e imutável, podendo variar consoante vários fatores, como, a título de exemplo, o tipo de em questão ou o meio eletrónico através do qual o ele é realizado. Contudo, é inquestionável que o tem consequências adversas para as vítimas.

\section{LimitaÇóES}

Durante a pesquisa e análise dos autorrelatos das vítimas, tornou-se claro que utilizar apenas as quatro emoçóes negativas apresentadas por Reio e Ortega (2016) seria insuficiente, já que existiam mais emoçóes e outros tipos de sentimentos reportados nos autorrelatos. Por esta razão, extraímos todas as emoçóes expressadas, explicita ou implicitamente, pelas vítimas nos seus autorrelatos.

Os autorrelatos nem sempre foram explícitos quanto aos sentimentos provenientes da vitimização e, por este motivo, é possível ter sido cometido algum erro na seleção das emoçóes - esta seleção de emoçóes consistiu na extração das emoçóes explícitas e das que se encontravam implícitas nos autorrelatos dos participantes.

A veracidade dos autorrelatos é uma grande limitação do nosso estudo, na medida em que, sendo autorrelatos recolhidos da Internet, não é possível garantir que os participantes não alteraram ou inventaram o que relataram.

A possível falta de precisão na construção dos autorrelatos é outra das limitaçóes, sendo que, ao terem sido recolhidos da Internet, não temos conhecimento da forma como foram criados, se houve algum tipo de planeamento ou preparação dos mesmos, nem se foi deixada de parte alguma informação que poderia ter sido essencial para uma melhor recolha dos nossos dados.

Durante a nossa investigação, não tivemos em conta os diferentes tipos de existentes em cada caso, o que pode

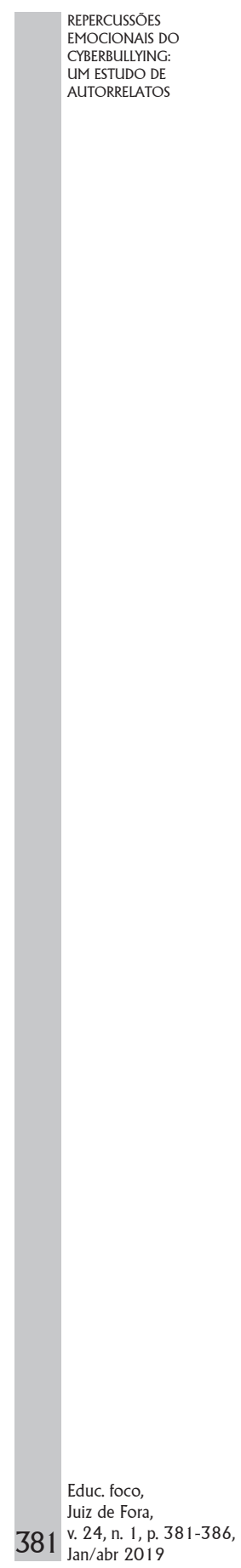


influenciar grande parte das emoçôes sentidas pelas vítimas. Como verificámos anteriormente, através de outros estudos, os diversos tipos de agressão influenciam, de facto, as emoçóes vividas pelas vítimas, devendo este ser um fator a considerar.

\section{IMPLICAÇÓES E INVESTIGAÇÓES FuTURAS}

O estudo das repercussóes emocionais é de extrema importância para uma melhor compreensão do , na medida em que se torna possível perceber a forma como as vítimas são afetadas e quais as repercussôes não-visíveis que este ato provoca nas mesmas.

Para além disto, é importante para a sensibilização para este fenómeno, de modo a demonstrar os danos emocionais reportados pelas vítimas, e talvez levar, deste modo, a uma maior compreensão da posição das mesmas, conseguindo, idealmente, uma diminuição dos casos de .

Este estudo, que aborda especificamente as emoçóes negativas sentidas pelas vítimas, e as interaçóes entre essas emoçôes, facilita estudos futuros na medida em que providencia informação sobre o que é de facto sentido pelas vítimas de , não sendo baseado em suposiçóes. $\mathrm{O}$ facto de ser baseado em autorrelatos poderá ser ainda útil em investigaçóes futuras, sendo que é escassa a investigação qualitativa na área baseada neste tipo de dados.

A interação entre as várias emoçóes reportadas pelas vítimas de poderá também ser alvo de uma investigação mais aprofundada, na medida em que poderá explicar a relação entre este tipo de violência e algumas das consequências sociais que traz, nomeadamente o isolamento social e a abstinência escolar.

Por fim, deixamos em aberto a questáo dos dois polos de emoçóes negativas associadas ao - o polo do medo e o polo da raiva -, sendo esta uma hipótese que nos surgiu ao longo da análise dos nossos resultados e que talvez possa ser uma questão que deva ser investigada a fundo. 


\section{CONSIDERAÇÓES FINAIS}

O nosso estudo teve como base tentar compreender se seria suficiente considerar apenas as quatro emoçōes negativas apresentadas por Reio e Ortega (2016) como as repercussóes emocionais para as vítimas de. Com a análise da nossa amostra de autorrelatos, concluímos que, na maioria dos casos, não se encontra apenas uma emoção, mas sim várias emoçóes interligadas.

Descobrimos outras emoçóes que aparecem sempre associadas a alguma das emoçôes negativas apresentadas por Reio e Ortega (2016) e, por vezes, também entre si - a vergonha, a dor, a culpa, o desapontamento, a vingança, a frustração, o desgosto e a angustia. Destacámos, ainda, nos nossos autorrelatos, a surpresa - uma das seis emoçóes básicas de Ekman e Friesen (1971), mas que Reio e Ortega (2016) não incluíram nas suas quatro emoçôes negativas.

Concluímos, através da análise dos autorrelatos recolhidos, que as quatro emoçóes negativas mais reportadas pelas vítimas de são a tristeza, o medo, a vergonha e o desapontamento. Levantámos a hipótese, ainda, da existência de dois polos de emoçóes negativas associadas ao - o polo do medo e o polo da raiva -, hipótese esta que requer investigação.

Este estudo traz, deste modo, uma melhor compreensão das repercussóes emocionais que o tem para as suas vítimas, no sentido em que expande o espectro das repercussóes nãovisíveis. Esperamos que também possa ser útil na sensibilização para este tipo de agressão $\mathrm{e}$, idealmente, uma possível diminuiçáo dos casos de .

\section{REFERÊNCIAS}

BULLYING STATISTICS. 2009. Disponível em: http:// http://www.bullyingstatistics.org

CAETANO, A. P. ; FREIRE, I.; VEIGA SIMÁO, A. M.; MARTINS, M. J. D.; PESSOA, M. T. Emoçóes 
no cyberbullying: um estudo com adolescentes portugueses. Educação e Pesquisa, v. 42, n. 1, p. 199-212, 2016.

CARAVITA, S. C.; COLOMBO, B.; STEFANELLI, S.; ZIGLIANI, R. Emotional, psychophysiological and behavioral responses elicited by the exposition to cyberbullying situations: Two experimental studies. Psicología Educativa, v. 22, n. 1, 49-59, 2016.

CROSS, D.; LESTER, L.; BARNES, A. A Longitudinal Study of the Social and Emotional Predictors and Consequences of Cyber and Traditional Bullying Victimisation. International Journal of Public Health, v. 60, n. 20, p. 207-217, 2015.

SOUZA, S. B.; VEIGA SIMÃO, A. M.; FERREIRA, P. C.; PAULINO, P. ; FRANCISCO, S. M. O cyberbullying em contexto universitário do Brasil e Portugal: vitimização, emoçóes associadas e estratégias de enfrentamento. Revista Ibero-Americana de Estudos em Educaçáo, v. 11, n. 3 (esp. ), p. 1674-1691, 2016.

CYBERBULLYING RESEARCH CENTER. Statistics, 2015. Disponível em: http://www.cyberbullying.org

BOURDEAUDHUIJ, I.; JACOBS, N. C.; DESMET, A.; GUNTHER, N. Comparing Associated Harm with Traditional Bullying and Cyberbullying: A narrative overview of mental, physical and behavioural negative outcomes. In VÖLLINK, T.; DEHUE, F.; MC GUCKIN, C. (Eds.). Cyberbullying: from theory to intervention (pp. 54-76). London: Routledge, 2015.

EKMAN, P. ; FRIESEN, W. V. Constants across cultures in the face and emotion. Journal of Personality and Social Psychology, v. 17, n. 2, p. 112-117, 1971.

GUALDO, A. M. G.; HUNTER, S. C.; DURKIN, K.; ARNAIZ, P. ; MAQUILÓN, J. J. The emotional impact of 
cyberbullying: Differences in perceptions and experiences as a function of role. Computers \& Education, v. 82, p. 228-235, 2015.

KOWALSKI, R. M.; WHITTAKER, E. Cyberbullying: Prevalence, Causes, and Consequences. In: KOWALSKI, R. M.; WHITTAKER, E. The Wiley Handbook of Psychology, Technology and Society (pp. 142-157), 2015.

MENESINI, E.; SPIEL, C. (2012). Introduction: Cyberbullying: Development, Consequences, Risk and Protective Factors. European Journal of Developmental Psychology, v. 9, n. 2, p. 163-167, 2012.

ORTEGA, R. et al. The emotional impact of bullying and cyberbullying on victims: a European cross $\$ national study. Aggressive behavior, v. 38, n. 5, p. 342-356, 2012.

PATCHIN, J. W.; HINDUJA, S. Bullies move beyond the schoolyard: A preliminary look at cyberbullying. Youth Violence and Juvenile Justice, v. 4, n. 2, p. 148-169, 2006.

REIO, T. G.; ORTEGA, C. C. Cyberbullying and its Emotional Consequences: what we know and what we can do. In: REIO, T. G., \& ORTEGA, C. C. Emotions, Technology, and Behaviors (pp. 145-158). San Diego, CA: Elsevier Academic Press, 2016.

SMITH, P. K.; MAHDAVI, J.; CARVALHO, M.; FISHER, S.; RUSSELL, S.; TIPPETT, N. Cyberbullying: Its nature and impact in secondary school pupils. Journal of Child Psychology and Psychiatry, v. 49, n. 4, p. 376-385, 2008. 
